Supplement of Biogeosciences, 14, 1333-1348, 2017

http://www.biogeosciences.net/14/1333/2017/

doi:10.5194/bg-14-1333-2017-supplement

(C) Author(s) 2017. CC Attribution 3.0 License.

(c) (i)

Supplement of

\title{
Modelling spatial and temporal dynamics of gross primary production in the Sahel from earth-observation-based photosynthetic capacity and quantum efficiency
}

Torbern Tagesson et al.

Correspondence to: Torbern Tagesson (torbern.tagesson@ign.ku.dk)

The copyright of individual parts of the supplement might differ from the CC-BY 3.0 licence. 


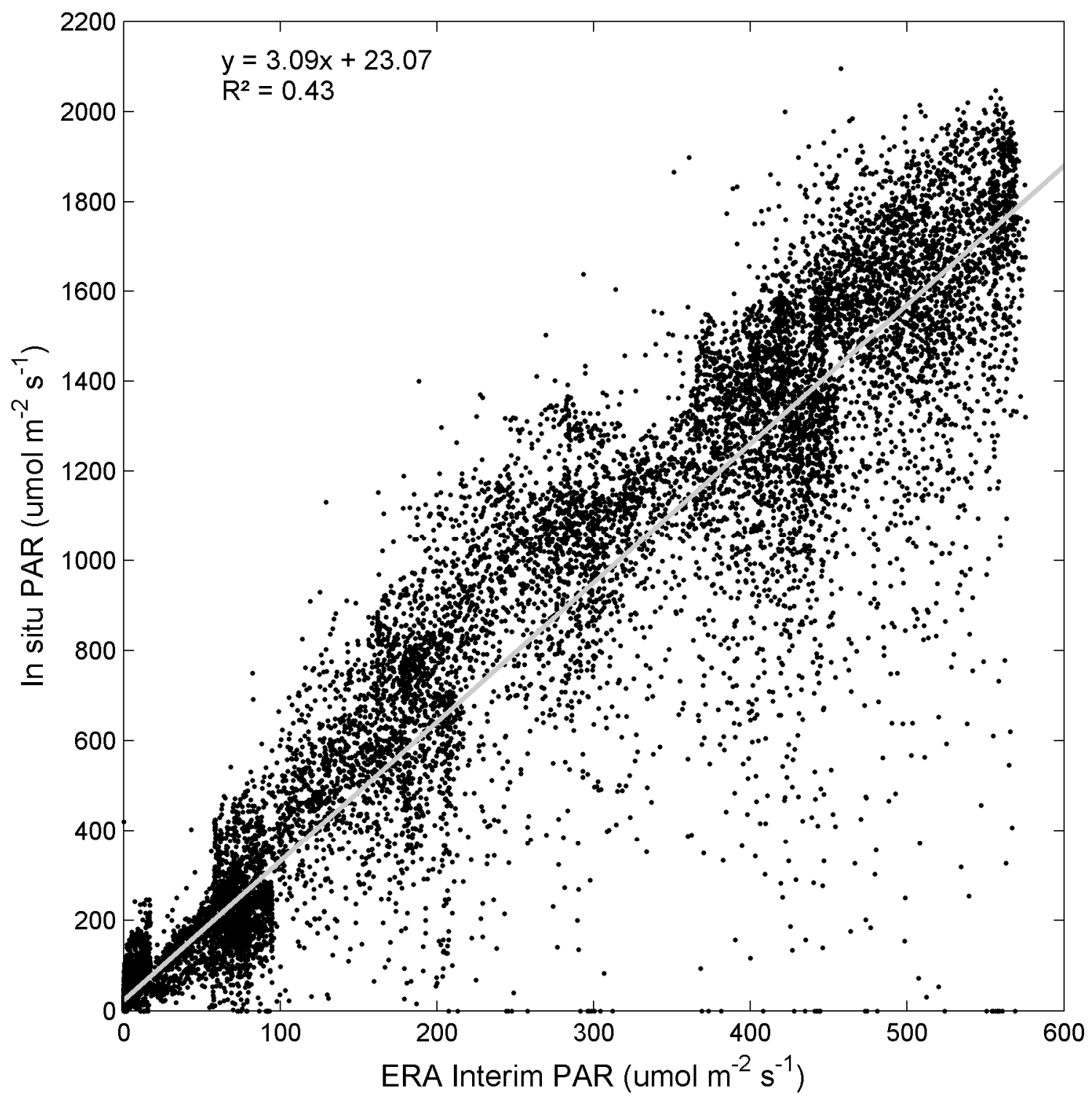

Figure S1. Photosynthetically active radiation (PAR) measured in situ against gridded ERA Interim ground surface PAR extracted for the six measurement sites (Fig. 1) across the Sahel from European Centre for Medium-Range Weather Forecasts, ECMWF (2016b). The grey line is the ordinary least square linear regression $\left(\mathrm{PAR}_{\mathrm{in} \mathrm{situ}}=3.09 *\right.$ PAR $_{\mathrm{ERA} \text { interim }}+23.07$; coefficient of determination $\left.\left(\mathrm{R}^{2}\right)=0.93 ; \mathrm{n}=37976\right)$. 

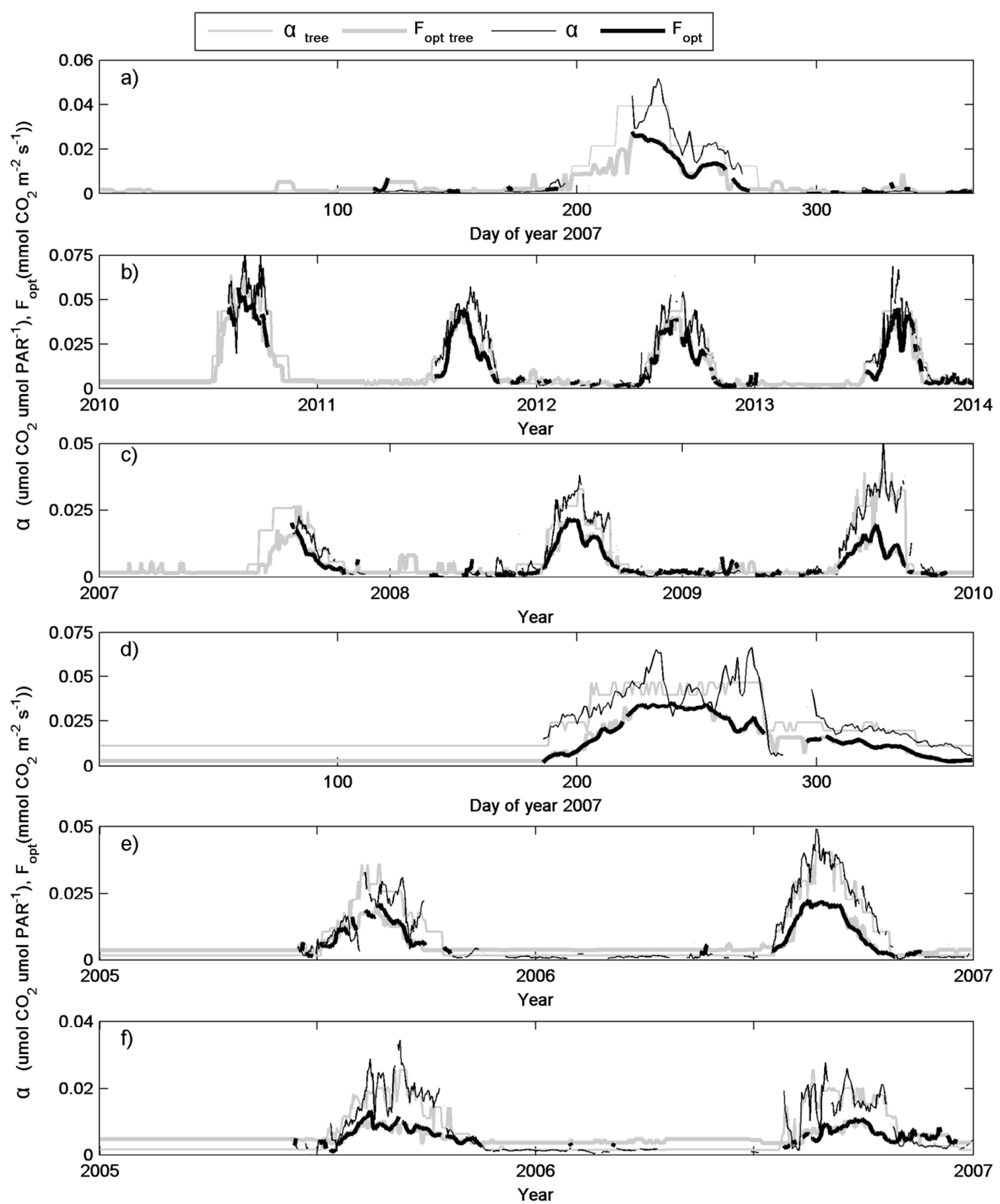

Figure S2. In situ measured photosynthetic capacity $\left(\mathrm{F}_{\mathrm{opt}}\right)$ and quantum efficiency $(\alpha)$, and Fopt and $\alpha$ as predicted by the regression trees $\left(\mathrm{F}_{\text {opt_tree }}\right.$ and $\alpha_{\text {tree }}$, respectively) for the six measurement sites. The sites are a) Agoufou (ML-AgG), b) Dahra (SN-Dah), c) Demokeya (SD-Dem), d) Kelma (ML-Kem), e) Wankama Fallow (NE-WaF), and f) Wankama Millet (NE-WaM). 